\title{
"Del infierno al paraíso": el destierro de presos políticos brasileños a Argelia en 1970
}

\author{
"From hell to paradise": the banishment of Brazilian political \\ prisoners to Algeria in 1970
}

\section{Débora Strieder Kreuz*}

\section{RESUMEN}

Este trabajo analiza el exilio impuesto a 40 militantes brasileños, Palabras clave: en junio de 1970, que fueron enviados a Argelia después de su dictadura, exilio, destierro. La dictadura de seguridad nacional de Brasil, como destierro, Argelia. sus congéneres del Cono Sur, utilizó el exilio como estrategia de exclusión, de forma que miles de ciudadanos debieron salir del país por la persecución sufrida, directa o indirectamente. El destierro, pena instituida en 1969, fue impuesta a 130 militantes intercambiados por autoridades diplomáticas extranjeras secuestradas por grupos de resistencia entre 1969 y 1971 y que se transformaron en exiliados, aunque anhelaran el retorno a Brasil para continuar la lucha. A partir de los relatos de los desterrados y de documentos producidos por los órganos de información y seguridad de la dictadura, se analiza el desarrollo de la acción de secuestro, el viaje a Argelia y las estrategias articuladas a partir de entonces por los “40", entendiendo el exilio en tanto un momento de resistencia.

\section{ABSTRACT}

This paper analyzes the exile imposed on 40 Brazilian militants Keywords: in June 1970, sent to Algeria after their exile. Like its Southern dictatorship, exile, Cone counterparts, Brazil's national security dictatorship used exile, Algeria. exile as a strategy of exclusion so that thousands of citizens had

\footnotetext{
Brasileña. Doctora en Historia, Universidad Federal de Rio Grande do Sul (UFRGS), Brasil. Académica e investigadora, Universidad Estadual de Piauí (UESPI), Brasil. ORCID: https://orcid.org/0000-0001-5540-8968. E-mail: debora_kreuz@yahoo.com.br * Nota editorial: Este artículo es la traducción en español del artículo original en portugués titulado “'Do inferno ao paraíso': o banimento de presos políticos brasileiros para a Argélia em 1970". La traducción fue realizada por Marcia de Mello con la conformidad de la autora del trabajo.
} 
to leave the country to avoid persecution, directly or indirectly. Banishment, a penalty instituted in 1969, was imposed on 130 militants exchanged for foreign diplomatic authorities kidnapped by resistance groups between 1969 and 1971 and who became exiles. However, they longed to return to Brazil to continue the struggle. Based on the exiles' accounts and documents, and the dictatorship's security organs, we analyze the development of kidnapping, the journey to Algeria, and the strategies articulated from then on by the " 40 ", understanding exile as a form of resistance. 
Entre 1964 y 1985 Brasil vivió una dictadura de seguridad nacional que revocó mandatos, encarceló, torturó, asesinó e hizo desaparecer a centenas de ciudadanos (CNV, 2014). Ante la amplia movilización social presente en el inicio de la década de 1960, llevada a cabo por diferentes grupos - trabajadores rurales y urbanos, estudiantes, militares de bajo grado, entre otros-, sectores militares, apoyados por una parte significativa de la burguesía nacional y de representantes del gobierno estadounidense, efectuaron un golpe contra el presidente João Goulart (Alves, 1985). A partir de entonces se inició un periodo en que las diferentes formas de manifestación fueron cada vez menos posibles. Tal periodo solo terminó con la elección indirecta, en 1985, de Tancredo Neves ${ }^{1}$.

El exilio, entendido como una estrategia de "exclusión institucional" (Sznajder y Roniger, 2013) también fue utilizado como una herramienta de persecución. Presente en la historia de las sociedades latinoamericanas desde el proceso de independencia en el siglo XIX, el exilio adquirió contornos específicos con la instauración de las dictaduras en las décadas de 1960 y $1970^{2}$, sobre todo por afectar a sujetos de diferentes clases sociales que actuaban en una esfera pública de carácter transnacional, denunciando lo que acontecía en sus países de origen (Sznajder y Roniger, 2013). Así, las acciones de los exiliados también merecen ser incluidas en las historiografías nacionales ${ }^{3}$, considerando que fueron fundamentales para los cambios, sobre todo relacionados con la apertura política y la adopción de nuevas estrategias de movilización política que ocurrieron.

De esta manera, inmediatamente después del golpe del $1^{\circ} \mathrm{de}$ abril de 1964, centenares de personas tuvieron que salir de Brasil. Eran, sobre todo, individuos identificados con el gobierno depuesto o con proyectos políticos de cuño reformista. El destino del exilio en ese momento fue, principalmente, Uruguay, ya que se creía que la intervención militar duraría poco tiempo y que las elecciones previstas para 1965 se realizarían. Rollemberg (1999) apunta que esa es la pri-

1 Para mayores informaciones acerca del proceso de transición política brasileña, ver Lemos (2018).

2 Acerca de una discusión más amplia sobre el tema del exilio, ver Jensen (2007) y Yankelevich, Jensen (2007).

3 Para una profundización de esta discusión, consultar Jensen (2011). 
mera generación de exilio. En cambio la segunda estaría caracterizada por militantes vinculados a la lucha armada y el destino principal sería Chile, sobre todo a partir del gobierno de Salvador Allende ${ }^{4}$. Con el golpe de Estado en este país se inicia un tercer momento: en el que los exiliados se trasladan al continente europeo, de forma que la gran mayoría abandonó la perspectiva de la lucha armada como herramienta para el combate a la dictadura ${ }^{5}$.

No obstante, a partir de 1969, otra herramienta jurídica fue utilizada por la dictadura para hacer que militantes que estaban presos hasta aquel momento salieran de Brasil: el destierro. Carlos Eduardo Fayal de Lyra $^{6}$, uno de los desterrados ${ }^{7}$ para Argelia ${ }^{8}$, definió de la siguiente forma su salida de Brasil, en donde se encontraba preso y fue bárbaramente torturado, y la llegada al país de exilio: "del infierno al paraíso". O sea, un abrupto cambio, que significó la permanencia de su vida después del periodo en prisión: la caracterización del infierno. La idea inicial, después de la llegada al territorio magrebino - el paraíso-, era retornar en breve a Brasil y seguir con la resistencia. Sin embargo, Fayal, como es conocido, solo volvería en 1979, luego de la promulgación de la Ley de Amnistía (Ley 6.683/79). O sea, con el destierro se inició un periodo de exilio que duró por casi diez años.

La institución de la pena de destierro fue una respuesta de la dictadura de seguridad nacional brasileña a las cuatro acciones de secuestro de autoridades diplomáticas llevadas a cabo por grupos de resistencia

$4 \quad$ Para comprender el proceso de exilio brasileño en Chile, ver Dias (2019).

5 Es importante considerar que esta no es una regla general, sino apenas un movimiento mayor detectado por las diferentes investigaciones acerca del exilio brasileño, sobre todo desarrolladas a partir de la idea de generaciones de exilio, mencionada por Rollemberg (1999).

6 Militante de la Ação Libertadora Nacional. Para mayores informaciones acerca dos diferentes grupos armados, consultar Gorender (1989) y Sales (2015).

7 En el texto utilizaré los términos "desterrados", "intercambiados" y "los 40" para referirme a los treinta y tres hombres, siete mujeres y cuatro niños que salieron de Brasil a partir de la acción. No es posible, en el espacio de un artículo, analizar la trayectoria individual de cada uno, aunque busque dar elementos que correspondan a diferentes perspectivas presentes.

8 Argelia, país del norte del continente africano, se independizó de Francia después de una violenta guerra de liberación entre 1954 y 1962, estableciendo un sistema de gobierno conocido como "socialismo árabe". A partir de entonces pasó a recibir exiliados y militantes de varios lugares del mundo, motivo por el que Amilcar Cabral la llamó la "Meca de la Revolución". En diferentes momentos del periodo dictatorial recibió exiliados brasileños, aunque en menor medida que otros países. 
armada entre septiembre de 1969 y enero de 1971. Los revolucionarios buscaban con tales actos, por un lado, intercambiar a los representantes diplomáticos por presos políticos enviándolos para el exterior y, por otro, divulgar manifiestos en cadena de radio y televisión, una estrategia para burlar la censura entonces reinante. Aun así, de acuerdo con Silva (2020), no es posible identificar de manera clara el papel que los secuestros tuvieron para la izquierda en aquel momento: si era una estrategia de resistencia o una tentativa de desestabilización de la dictadura. La autora afirma que: "Aunque estuviesen imbuidos de una voluntad revolucionaria, las dificultades llevaron a que los secuestros fueran defensivos" (Silva, 2020: 1648). Para Resende (2019), debemos comprender los secuestros como una estrategia utilizada por diferentes grupos, sobre todo en el contexto de la Guerra Fría. De forma que no fueron fenómenos aislados en Brasil, sino que se propagaron por diferentes países.

En el territorio brasileño, la primera de las acciones tuvo como objetivo el embajador estadounidense en Brasil, Charles Burke Elbrick ${ }^{9}$, y su resultado fue la liberación de 15 presos $^{10}$ que fueron enviados a México. La segunda, con el secuestro del cónsul japonés en São Paulo, Nobuo Okuchi, liberó cinco presos, que fueron también enviados al país norteamericano. La tercera, que será objeto del presente texto, fue responsable por el intercambio de 40 presos, los cuales fueron enviados a Argelia en junio de 1970. Por último, 70 militantes fueron enviados para Chile después del secuestro del embajador suizo, entre diciembre de 1970 y enero de $1971^{11}$. Es importante resaltar que el aparato represivo, durante y después de las acciones, desencadenaba una feroz persecución, de manera que muchos de los militantes que de ellas participaron terminaron presos y asesinados. Para responder a las acciones de secuestro, se instituyó, en 1969, la pena de destierro, a partir del Acto Institucional número 13:

"Art. 1: El Poder Ejecutivo podrá, mediante propuesta de los Ministros de Estado de Justicia, de la Marina de Guerra, del Ejercito o de

9 Para mayores informaciones sobre esa acción, consultar Resende (2019).

10 El documental Hércules 56, de Silvio da Rin, basado en el libro del mismo nombre, retrata ese momento.

11 Este episodio está retratado en el documental Setenta (2013), bajo la dirección de Emilia Silveira. 
la Aeronáutica Militar, desterrar del territorio nacional al brasileño que, comprobadamente, se torne inconveniente, nocivo o peligroso para la seguridad nacional"12.

Al día siguiente, a partir del Acto Institucional número 14, fue instituida la pena de muerte: "No habrá pena de muerte, de prisión perpetua, de destierro o confiscación, salvo en los casos de guerra externa psicológica adversa, o revolucionaria o subversiva en los términos que la ley determine"13. O sea, en caso de que los autores del secuestro fuesen capturados, lo que acontecería en poco tiempo, podrían ser condenados a muerte, teniendo en cuenta que, en el contexto, era considerado de guerra subversiva ${ }^{14}$.

Por su parte, el destierro, figura jurídica prohibida por el Derecho internacional, retiraba la nacionalidad de los sujetos, por lo tanto, también los derechos derivados de ella. Los desterrados también pasaron a ser uno de los principales enemigos de la dictadura. Así, en los relatos aparecen constantes amenazas de que, en caso de que intentasen retornar a Brasil, serían asesinados sumariamente. Rollemberg (1999) apunta que, ante la ONU, continuaban con nacionalidad brasileña, aunque en la mayoría de los casos pasaron años hasta que tales sujetos consiguieron algún tipo de documento que comprobara su nacionalidad. Mauricio Paiva, desterrado en el penúltimo secuestro, rememora tal condición:

"De aquel momento en adelante, a la par de la condición común de desterrados y enemigos de primera grandeza del régimen brasileño, cada uno viviría su propio drama. (...) Que banido era sinónimo de desterrado, de apátrida, era una definición que se encontraba en cualquier diccionario. Lo que no sabíamos era que ese estigma nos vinculaba al destino de no-ciudadanos, que sin-Patria es lo mismo que sin identidad nacional y sin derechos de ninguna especie. No sabíamos que estábamos colocados en el compartimiento de los muertos-vivos y que nuestra existencia sería menos reconocida por

12 Brasil. Acto Institucional No13. Disponible en: http://www.planalto.gov.br/ccivil_03/ait/ait-13-69.htm. Revisado el 20-XII-2019.

13 Brasil. Acto Institucional No14. Disponible en: http://www.planalto.gov.br/ccivil_03/ait/ait-14-69.htm. Revisado el 20-XII-2019.

14 Es importante remarcar que la pena no fue aplicada formalmente, aunque las prisiones fueron seguidas de tortura, asesinato y desaparición. 
las leyes de las Naciones que por los archivos de la policía de casi todo el mundo y, consecuentemente, por las listas negras de embajadas y aeroportuarios" (Paiva, 2004: 90).

O sea, el destierro pasó a otorgar una identidad para los sujetos: como revolucionarios que luchaban por su país, en algunos casos; como enemigos de primera grandeza de la dictadura brasileña, en otras. El hecho de "haber salido en el alemán" o "en el suizo" hace que los desterrados pertenezcan a un grupo y que podamos identificar una trayectoria con elementos en común: militancia contra la dictadura, prisión, tortura (Silva, 2020).

A partir de estas consideraciones iniciales, el presente texto buscará comprender el proceso de destierro de los 40 militantes intercambiados por el embajador alemán Ehrenfried Anton Theodor Ludwig von Holleben ${ }^{15}$, que ocurrió en Río de Janeiro entre el 11 y 15 de junio de 1970, a partir de una acción conjunta de dos organizaciones de lucha armada, la Vanguarda Popular Revolucionária (VPR) y la Ação Libertadora Nacional (ALN).

Para la realización de esta propuesta serán utilizadas entrevistas realizadas por la autora, obras de memorias publicadas en diferentes momentos, y que constan en la bibliografía al final del texto, así como documentos de los órganos que componían la llamada "comunidad de informaciones" ${ }^{16}$ de la dictadura que seguían a los desterrados, y artículos periodísticos. Es importante resaltar que cada tipo de fuente necesita un cuidado teórico-metodológico específico, que será mencionado a lo largo del texto.

El objetivo de este artículo es contribuir al debate sobre el exilio brasileño de forma general y sobre el destierro de forma específica, considerando que solo recientemente la historiografía se ha dedicado

15 Llegó a Brasil en 1966 y sirvió hasta 1970, luego del secuestro, cuando fue designado para ser embajador en Portugal.

16 De acuerdo con Ishaq, Franco y Sousa (2012) la "comunidad de informaciones" reunía el Serviço Nacional de Informações (SNI), Centro de Informações do Exército (CIE), Centro de Informações da Marinha (CENIMAR), Centro de Informações e Segurança da Aeronáutica (CISA), Divisões de Segurança e Informações (DSI), Centro de Informações do Exterior (CIEx), y los órganos estaduales, como los Departamentos de Ordem Política e Social (DOPS), o sea, órganos responsables por la recolección y difusión de informaciones, con el objetivo de instrumentalizar acciones represivas contra los considerados "enemigos de la dictadura". 
a este tema. Así, buscaremos comprender de qué manera ocurrió el proceso de destierro, la llegada al país de destino y las diferentes estrategias utilizadas por los desterrados para continuar en el proceso de resistencia a la dictadura.

\section{El secuestro del embajador alemán y el destierro}

Durante el curso del Mundial de Fútbol de México 1970, en el cual Brasil se consagraría campeón, los dos grupos armados, la VPR y la ALN, llevaron a cabo la acción de captura del embajador alemán en Brasil, cuyo desarrollo se dio de forma rápida, teniendo en cuenta que algunos meses antes la planificación había caído en manos de la represión. Un factor político también influyó en la rapidez de la resolución del secuestro: las negociaciones de un acuerdo nuclear que ocurría entre Brasil y la República Federal de Alemania. Maria do Carmo Brito, militante de la VPR y una de las intercambiadas recuerda:

"La noche que pasé siendo interrogada por el capitán Guimarães, apenas llegué de vuelta al DOPS de Río [de Janeiro], todas las preguntas eran en torno del secuestro del embajador alemán, cuyos planes estaban conmigo, y que fue hecho igualito, porque Juares murió, entonces nadie de la unidad de él cayó.

Pero yo vivía un pandemonio tan grande, que ni me había dado cuenta.

¿Cómo podría imaginar que habían hecho la mismísima acción, con el mismo embajador, todo igual? (99).

(...) Fue el secuestro más rápido de la historia, por la firma del acuerdo nuclear con Alemania, para las usinas de Angra I y II pero nadie sabía eso. Entonces, liberaron a todo el mundo rapidito, porque el acuerdo estaba en juego. Los compañeros apuntaron a lo que vieron y dieron en lo que no vieron" (Vianna, 2003: 101).

El secuestro y su desarrollo fueron seguidos por los grandes medios de comunicación. En el periódico O Estado de São Paulo, del 13 de junio, se afirmaba que el nombre de von Holleben figuraba en una lista de autoridades que serían secuestradas por los “terroristas" ${ }^{17}$. En

17 El término "terroristas" era utilizado por parte de los medios de comunicación como forma de deslegitimar las acciones políticas de las diferentes organizaciones de 
cuanto los militantes eran representados como violentos, varias fotos y una entrevista con la esposa del diplomático buscaban sensibilizar a los lectores. Aun, en la edición del día 13 se mencionaba que el gobierno "demuestra estar dispuesto a todo para conseguir la liberación de von Holleben" (Gôverno atende condições. O Estado de S. Paulo, 13VI-70, tapa). Al día siguiente, el periódico informaba que "Todas las condiciones son aceptadas" (12), ya que el gobierno brasileño deseaba que el embajador fuera liberado lo más rápidamente posible. Después del éxito de las negociaciones, Alfredo Syrkis, que participó de la acción, recuerda:

“En el cuarto del fondo, Bacuri [el comandante militar de la acción] pasaba en limpio la lista, en una hoja de papel de seda, digitando apenas con los indicadores en la vieja Olivetti, escribiendo sin errores, en mayúsculas, los nombres de los cuarenta compañeros que íbamos a remover del Gulag patropi para las Árabias, por la Varig [aerolínea brasileña]" (Syrkis, 1980: 189). ${ }^{18}$

La negociación realizada por parte del gobierno dictatorial dejaba a algunos sectores de las Fuerzas Armadas incómodos, debido a la postura que definían como capitulación ante los militantes, o sea, era inconcebible negociar con "terroristas". Los relatos de violencia sobre las personas que serían intercambiadas demuestran ese elemento. De acuerdo con Carlos Fayal, cuando salió la noticia del intercambio hubo una simulación de fusilamiento:

"Y en ese momento, la mañana siguiente... de la historia del secuestro... fue hasta rápido... fue dos días después... sí... entraron los tipos en mi celda... los tipos de civil, todos bien mozos, así... anteojos oscuros, ametralladora en mano, qué sé yo... entra otro y dice: 'Sigue aquí. Sin explicar mucho. Yo seguí. Ahí ellos... gira para acá, gira para allá... nunca había caminado tanto en aquellos caminos, abajo de la PE, qué sé yo. Entonces ellos dijeron: “¿Qué es lo que

izquierda. Sin embargo, debemos considerar también la censura y autocensura que predominaban. Ver Aquino (2002).

18 Varias reflexiones sobre el discurso de Syrkis pueden ser realizadas: la primera sobre la forma con que las prisiones son nombradas - gulag patropi-, relacionándolas con las prisiones del periodo stalinista, teniendo en consideración que los grupos armados querían distanciarse de tal relación, así como a la sátira en relación con Brasil. La segunda aparece cuando se menciona a "las Arabias", en una alusión estereotipada a Argelia. 
tienes para decir? Tú vas a ser fusilado aquí" Ahí yo dije... "Bueno, algo salió mal... pero bueno, después de lo que pasé resuelve de una vez el asunto". ¿Qué voy a decir? Ahí el tipo me puso el revólver y tac! Saltó. Entonces dijo: "Barba en 1 minuto". Ahí yo dije: "Ah, se jodieron, no?". Me mandó a hacer la barba en 1 minuto, ahí se jodieron, no? Entonces volví y fui avisándoles a todos 'Están fusilando a todo el mundo de onda acá. Empezamos a los golpes lógicamente, pero avisé ahí. Les acabé la fiesta de hacer ese terror. Entonces fue así" (Fayal, 2017).

Daniel Aarão Reis Filho, militante del MR-8, también rememora:

“...pasamos una noche en el DOI-CODI, donde fuimos debidamente golpeados y barbarizados, amenazados de fusilamiento. Algunos camaradas pasaron por la simulación de fusilamiento. Yo no pasé por esa experiencia, pero fui golpeado, fui maltratado. Porque los policías estaban indignados con el hecho de que el gobierno había capitulado frente a las exigencias de los revolucionarios. Entonces... no fue fácil pasar esa noche ahí. Pero al día siguiente por la mañana, fuimos todos agrupados en el patio del DOI-CODI, aquel facineroso llamado capitán Gomes Carneiro, creo que está vivo todavía, hizo un discurso... denunciando al gobierno como débil y que nosotros estábamos siendo liberados, que eso era un absurdo, que ellos se esforzaban tanto para agarrarnos y ahora íbamos a ser todos liberados, y avisaba que quien volviera sería inmediatamente asesinado. Bueno, nosotros entramos entonces en los autos, en los furgones, y fuimos para el Galeão [aeropuerto en Río de Janeiro], donde fuimos fotografiados y demás. Es interesante observar que en Ilha Grande todavía, nosotros fuimos muy fotografiados, sí... ese ejercicio se repitió en el DOI-CODI. Fotografiados por brasileños y por agentes de los Estados Unidos, que no escondían su identidad. Conversaban entre sí en inglés y etc." (Aarão, 2017).

Percibimos, a partir de la memoria de Daniel Aarão, que la violencia a la que los militantes fueron sometidos remitía a una victoria revolucionaria, aunque fuese revertida en breve. El propio hecho de que el narrador se remita todavía a su identidad "revolucionaria" es indicativa de la forma en la que comprende la acción. Su narrativa conjuga elementos del pasado y del presente: el hecho de nombrar al torturador y mencionar que aún está vivo, refleja posiblemente una demanda 
de justicia relacionada con los crímenes cometidos por los agentes del Estado en ese periodo, lo cual en Brasil todavía no ocurrió. También es importante mencionar la participación de estadounidenses en el proceso, teniendo en cuenta la cooperación que existió. La referencia a las fotografías alude a los álbumes de desterrados, que eran compilados y distribuidos por las embajadas brasileñas como forma de cercenar cualquier tentativa de conseguir documentos ${ }^{19}$. Es importante resaltar que incluso los cuatro niños que salieron también fueron fotografiados, o sea, eran considerados "miniterroristas" ${ }^{20}$ por la dictadura, por lo tanto, debían también ser monitoreados. Ladislau Dowbor también relata el momento de partida y la preocupación de los militares con las marcas de la tortura que permanecían en su cuerpo:

"Mira, ah... nosotros fuimos inspeccionados... los que estaban en São Paulo, ¿sí? Por lo tanto, en el DOPS allí, nos llevaron a un piso de arriba, a un grupo, ¿no?... que iba a venir de São Paulo. A nosotros nos iban a llevar a Río [de Janeiro], para embarcar para Argelia y... un general vino a inspeccionarnos ¿no? Ah... ahí ellos... mirando las cosas... ahí mirando... yo tengo eso aquí... ¿ está viendo eso aquí? Da para ver ¿no? [muestra la canilla con una cicatriz]. Esto aquí era un hueco. Esto eran quemaduras de tercer grado de choque eléctrico. Eso que los cables estaban envueltos en algodón mojado... para no dejar marcas. Era un huecazo de este tamaño que estaba aquí, sangrando... evidentemente... esa cosa. Él vio eso aquí ¿no?, me miró y dijo “iQué trabajo de puerco!”. O sea, el problema para él no era la tortura, el problema es que habían dejado la marca (risas). Porque normalmente... yo había recibido un tratamiento especial, no por mí o por alguna importancia, sino porque ellos pensaban que yo sabía donde estaba el dinero. Y no era por razones políticas, sino para llegar... para meter la mano en el dinero, ¿entiende? El bandidaje era generalizado. Se llamaban fuerzas del orden $i$ no? En fin. Sí... y el resultado era ese. Entonces nos juntaron allí y después

19 Archivo Nacional. Centro de Informaciones de la Aeronáutica. Elementos banidos do território nacional. 24-VI-1970. Identificación: BR_DFANBSB_Z4_SNA_TRR_0018_ p161-162.

20 La expresión es de Zuleide Aparecida do Nascimento, una de las niñas que salió en la acción. En la obra Infância Roubada encontramos relatos de los niños que salieron en ese momento. Los cuatro eran nietos de Tercina Dias de Oliveira, militante de la VPR y que, debido a su insistencia, consiguió llevarlos. 
fuimos llevados, a la noche, para el campo de Marte y del campo de Marte fuimos llevados... ah... en avión militar, en fin... sin asiento, simplemente sentados ahí en el piso... en el metal ahí. Nos llevaron a la Base Aérea del Galeão, para la parte militar del Galeão, y nos quedamos aguardando el embarque para Argelia. Hay esa foto famosa del grupo ahí... en realidad fue allí que nos juntamos los 40. Algunos no se conocían, evidentemente... para embarcar ¿no?” (Dowbor, 2017).

El dinero al que Dowbor se refiere tiene relación con una acción realizada por su organización, la VPR, en 1969, en la cual US\$2,4 millones de dólares fueron expropiados (Maciel, 2015). Se especulaba que él sabría donde estaría ese dinero y los agentes lo querían, por eso la afirmación de que "el bandidaje era generalizado". En este punto es posible pensar que el hecho de ser Argelia el destino del secuestro solicitado por el grupo se vinculaba con que Miguel Arraes ${ }^{21}$ sería el fiel depositario de una parte del dinero, y solo liberaría el acceso a partir del contacto con algunos miembros de la organización (Vianna, 2003). Asimismo, además de Argelia, México fue uno de los países que figuraba en la lista de destino. La fotografía a la que Ladislau se refiere es la Figura 1, cuya publicación también era una exigencia de los intercambiados, en la que podemos ver a los desterrados, algunos haciendo el famoso saludo con la "V" de victoria. En el lado derecho de la fotografía vemos a la única militante sentada, Vera Silvia Magalhães, del MR-8, la cual, debido a la tortura, no conseguía caminar:

21 Gobernador del Estado de Pernambuco en el momento del golpe. Cayó preso y consiguió salir para Argelia a mediados de 1965. A partir de entonces aglutinó en torno de sí a un grupo de exiliados, e inició una serie de articulaciones con el objetivo de denunciar la dictadura a nivel internacional. Para mayores informaciones sobre su exilio, ver Kreuz (2020). 


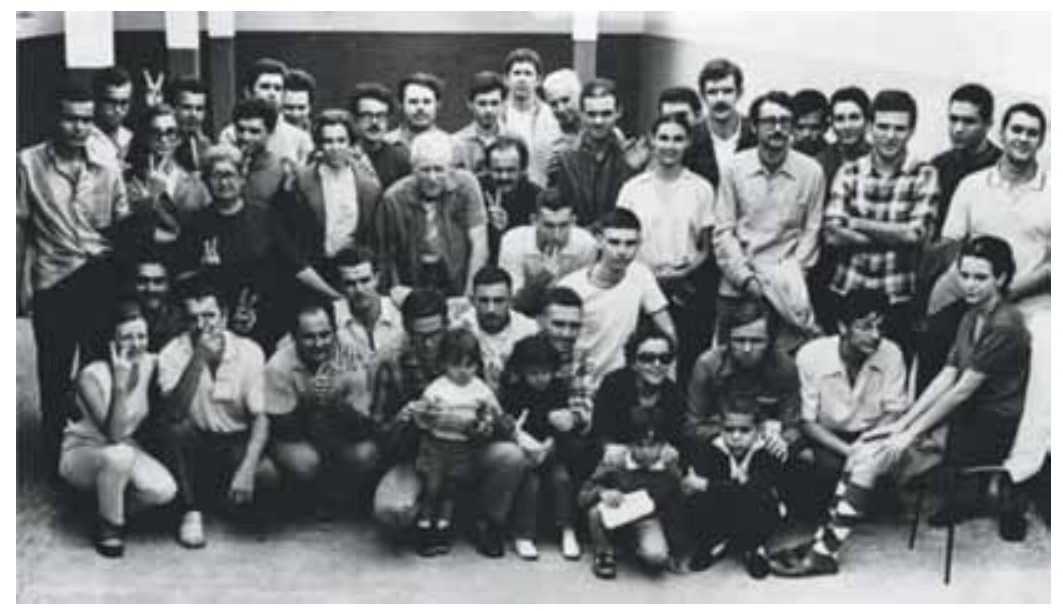

Figura 1. Los 40 desterrados antes del embarque.

Fuente: Disponible en http://memorialdademocracia.com.br/card/40-sao-trocadospor-embaixador-alemao. Revisado el 30-XI-2019.

\section{Argelia: destino de los desterrados}

Después de la reunión, los “40” fueron enviados a Argelia. Fueron esposados de a dos y acompañados por un agente, o sea, 20 dúos y 20 agentes. Durante el viaje, estos últimos intentaban obtener informaciones sobre las acciones que serían tomadas. Cid Benjamin afirma:

“...en ciertos momentos del viaje conversé con un oficial que se sentó a mi lado. Era de los que decían que "respetaban al enemigo". Me preguntó si yo volvería a Brasil clandestinamente. Frente a la respuesta positiva, me advirtió: -Te quiero decir una cosa: el precio de que ustedes salgan es, de ahora en adelante, no crear más problemas. Los importantes serán asesinados.

-Ya me lo esperaba- respondí" (Benjamin, 2013: 144).

La decisión de asesinar a los desterrados que retornaran a Brasil fue tomada y era de conocimiento de todos los niveles ${ }^{22}$, teniendo en cuenta que eran considerados uno de los mayores enemigos de la

22 Conforme con el documento de la Central Intelligence Agency (CIA) recientemente hecho público. Para mayores informaciones, consultar http://g1.globo.com/jornalnacional/noticia/2018/05/documento-da-cia-diz-que-geisel-manteve-execucoes-de-subversivos.html. Revisado el 30-XI-2019. 
dictadura, ya que participaban de organizaciones de lucha armada y anhelaban la vuelta al país para la continuidad de la lucha. Después del destierro, con la discordancia de los sectores represivos, esa sería la alternativa para que episodios de este tipo no se repitieran. De esta forma, era fundamental para los órganos de información descubrir eventuales rutas de retorno, como percibimos en las memorias de Cid Benjamin. Maria do Carmo Brito también recuerda: "Todavía faltaban algunas horas para la libertad. Fue cuando algunos policías abrieron mapas enormes y comenzaron a preguntarnos a cada uno de los presos: ¿por dónde van a entrar a Brasil de vuelta para continuar con la guerrilla?" (Vianna, 2003: 103). O sea, los agentes sabían que por lo menos algunos del grupo intentarían retornar y era importante descubrir cómo. Luego del viaje, un informe producido por los agentes de la Aeronáutica que acompañaron a los desterrados informaba que:

"5- Tomamos todas las precauciones con los terroristas, evitando la posibilidad de actos de violencia, que forzasen el avión a alterar su ruta, en dirección a MÉXICO. Ese propósito estaría plenamente justificado, considerándose el efecto publicitario que el desembarque del "EQUIPO DE LOS 40" causaría, al ocurrir en un país en que toda la prensa internacional se encuentra reunida, en virtud de la disputa del Mundial. (...)

14- Durante nuestra permanencia, por el tiempo de 1,15 horas, en el Aeropuerto Internacional de Argel, la aeronave estuvo bajo rigurosa vigilancia, obviamente, para evitar cualquier sorpresa en el retorno. (...) Opiniones Generales:

-Ellos volverán con documentos falsos; -nuevo secuestro liberará mayor efectivo [...]; -las autoridades argelinas no les dieron mucha atención a los subversivos [...]; -la tripulación del avión y los agentes recibieron souvenirs: 3 botellas de vino, una cesta con frutas (naranjas y ciruelas); algunos recibieron capas [...]; -los niños ya tienen nombres de guerra; -ruta de retorno a Brasil: ARGEL-MADRID-HABANA-MÉXICO-BRASIL [...] -los próximos secuestros serán: -autoridades de la represión — para ajusticiamiento; -industriales y familiares - para obtención de dinero; -diplomáticos - para el intercambio de presos. -Permanecerán 6 
meses en Argelia en entrenamientos y retornarán a continuación para Brasil" 23 .

Es importante que reflexionemos, aunque sea de forma breve, sobre la naturaleza de la fuente analizada: un informe producido por agentes vinculados a una de las fuerzas represivas (CISA) y que fue responsable del transporte de los desterrados. Así, no podemos analizarlo aisladamente, ya que componía un conjunto documental cuya lógica de producción debe ser comprendida por el investigador (Camargo, 2009). Tales documentos, aunque no estén firmados, fueron producidos por sujetos que trabajaban en espacios donde la represión era la marca y que deberían justificar su propia existencia, resaltando su importancia. Se destaca la preocupación con una eventual acción para alterar la ruta del avión con el objetivo de resaltar todavía más la llegada de los desterrados. También, aparece nuevamente la preocupación con los posibles trayectos de retorno, así como con los niños, los cuales supuestamente ya estarían inseridos en las organizaciones. Finalmente, es evidente la preocupación sobre las acciones que serían realizadas, sobre todo los secuestros, que se habían transformado en una gran inquietud. Un punto de divergencia entre las memorias de los desterrados y lo destacado en el documento es el tratamiento dispensado por las autoridades argelinas. De acuerdo con Daniel Aarão:

"Cuando llegamos allá a Argelia tuvimos el placer de ver el gobierno argelino, porque los policías brasileños querían descansar... salir, ¿no? Hacer compras en el free shop, pasar el día en Argelia, pero el gobierno argelino lo prohibió. Mandó el avión a dar la vuelta y picar para Brasil. Cargar combustible y volver a Brasil. Ellos no tuvieron ni el derecho de tocar el suelo argelino. Entonces ahí... nos sacaron las esposas, ¿no?... nosotros desembarcamos y enseguida había una gran colectiva de prensa... muchos representantes de los medios, ¿no?, muchas fotos de esa época sobre eso" (Aarão, 2017).

Existe una nítida discrepancia respecto del análisis del tratamiento dispensado a los recién llegados: en la memoria de los desterrados, los agentes del Estado eran mal vistos, mientras que ellos tuvieron un

23 Archivo Nacional, Brasil. Acervo de los Órganos de Informaciones del Régimen Militar. Centro de Informaciones de la Aeronáutica. Transporte de Banidos para a ARGÉLIA. 08-VII-1970. Identificación: BR_AN_BSB_VAZ_109_0139. 
cambio de estatus, pasaron de desterrados a héroes. Paiva también rememora: "Quién se iría a imaginar, por ejemplo, que yo un día estaba atrás de las rejas, en una minúscula celda, y al otro día estaría en Argelia, con el ancho mundo por delante, que un día era tratado como desterrado y al siguiente, sería tratado como héroe" (Paiva, 2004: 22). La Figura 2 ilustra la diferencia con relación a la primera imagen: más militantes conmemoran la llegada, con una nítida expresión de alivio. Percibimos también que Cid Benjamin alza a Vera Silvia Magalhães. Él recuerda ese momento:

"Al desembarcar en Argelia, nos vimos delante de un batallón de periodistas de agencias internacionales. Fui llamado para cargar a Vera Sílvia, imposibilitada de caminar debido a las torturas. Hasta que consiguieron una silla de ruedas, yo la llevé en los brazos por la pista del aeropuerto. La escena dio margen a la más expresiva fotografía de nuestra llegada y ocupó las páginas de periódicos del mundo entero" (Benjamin, 2013: 144).

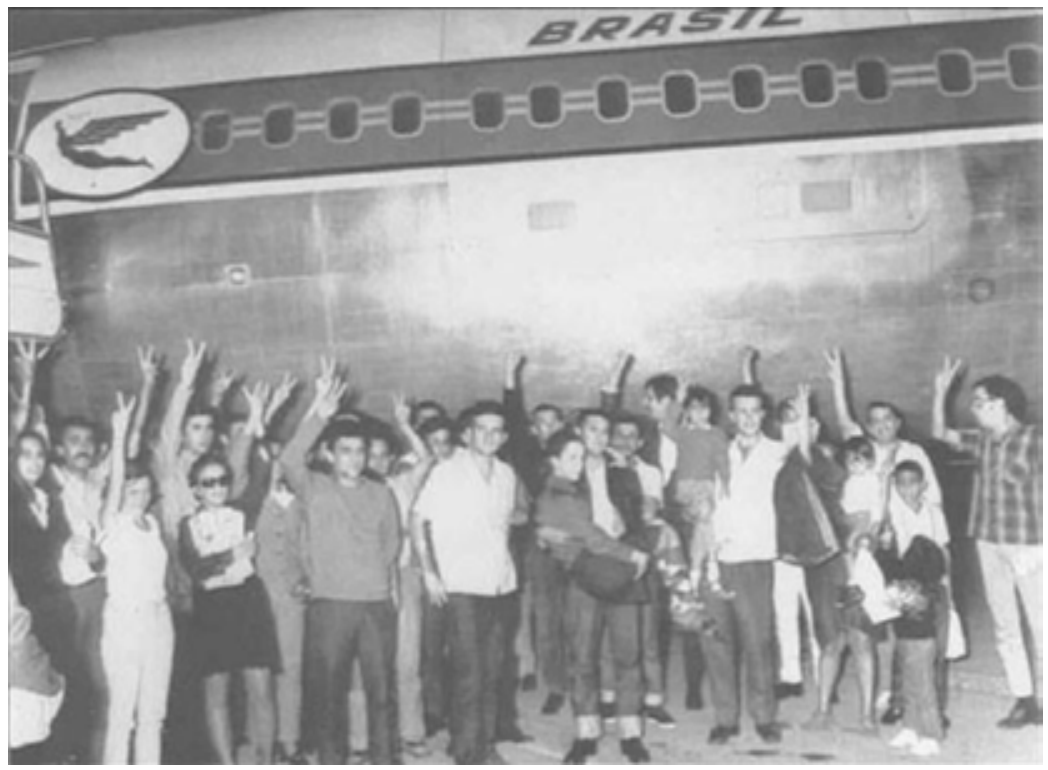

Figura 2: Los desterrados después de la llegada.

Fuente: Disponible en https://www.em.com.br/app/noticia/politica/2012/04/08/interna_politica,287584/relatorio-inedito-do-governo-militar-acompanhou-todos-os-passos-da-esquerda-no-brasil.shtml. Revisado el 20-III-2018. 
Inmediatamente luego de la llegada, se formó un grupo con el objetivo de dar declaraciones a la prensa de diferentes lugares del mundo que allí se encontraba. El grupo estaba compuesto por Apolônio de Carvalho $^{24}$, Ladislau Dowbor y Fernando Gabeira, ya que ellos conseguían comunicarse en otros idiomas, como francés e inglés. Denunciaron a la dictadura brasileña, sobre todo en relación con la violencia sufrida, cuyo mayor ejemplo era la presencia de Vera Sílvia, y colocaron las acciones de los grupos como resistencia a la dictadura y al imperialismo estadounidense. En la memoria de Apolônio:

“Ladislas Dowbor, Gabeira y yo somos los portavoces del grupo. A pesar de que mi cabello blanco me da la condición de decano. Agradezco el recibimiento, explico la razón de ser de los secuestros de embajadores, la situación de Brasil bajo la dictadura militar. Y las amenazas que pesan sobre los compañeros que se quedaron. Denuncio la muerte de algunos. Dado el cansancio y las emociones, mi voz es un susurro apenas ampliado por los micrófonos" (Carvalho, 1997: 210).

La noticia de la llegada de los intercambiados a la capital de Argelia fue conmemorada por los militantes que participaron de la acción: "Me despertaron horas más tarde, el aparato en clima carnavalesco. Las agencias internacionales acababan de confirmar la llegada del Boeing en el aeropuerto de Argel. ¡Misión cumplida!" (Syrkis, 1980: 192). El periódico O Estado de São Paulo también referenció la llegada con la publicación de la foto. Después del éxito de la acción el embajador alemán fue liberado.

La memoria de la llegada es de Ladislau Dowbor, que relaciona la llegada el día 16 de junio con la denuncia inmediata que se realizó, en vista de las marcas de la violencia que todavía estaban en los cuerpos de aquellos hombres y mujeres:

"A las cuatro de la mañana desembarcamos en Dar el Beida, aeropuerto de Dar el Beida, en Argel, donde estaba la prensa del mundo entero. Impresionante. El mundo entero. Toda la prensa mundial

24 Considerado el más ilustre de los desterrados, había luchado en las Brigadas Internacionales durante la Guerra Civil Española, en la resistencia francesa contra el nazismo y, durante la dictadura, había creado el Partido Comunista Brasileño Revolucionario. Para mayores informaciones sobre su trayectoria, ver Carvalho (1997). 
estaba ahí, ¿no? Porque es muy raro sacar gente de los sistemas de tortura y directamente decir “Miren, aquí están”. Quiero decir... frente a todo lo que, lo que la diplomacia brasileña y todo, los periódicos brasileños y los corresponsales internacionales en Brasil decían que no, que estaban reestableciendo el orden, en fin, que eran desterrados terroristas, esas cosas" (Dowbor, 2017).

A partir de entonces, el grupo fue alojado en una colonia de vacaciones, Ben Aknoun, localizada en los alrededores de Argel. Ese periodo fue considerado por la mayoría como un intervalo, con el objetivo de recuperarse de la violencia sufrida. Las memorias sobre ese momento inicial (Vianna, 2003; Vieira, 2008; Dowbor, 2000) son de mucho alivio y relajación, teniendo en cuenta la violencia y traumas acumulados, desde la prisión hasta el viaje. Lizst Vieira (2017) afirmó: "Yo no sé nada de árabe, pero ese nombre nunca me olvidé: Ben Aknoun". O sea, poder salir de la prisión e ir para un espacio seguro fue determinante en la vida de esos sujetos. Dowbor resalta que les fueron ofrecidas condiciones de dignidad después de meses de constante violencia, elemento que evoca memorias complejas y cargadas de ambigüedad, teniendo en consideración los sentimientos buenos y malos que son rememorados:

"Después de la llegada tuvimos un montón de entrevistas en el aeropuerto y después nos llevaron a un lugar... un lugar muy simpático, muy bucólico, en la parte alta de Argel, ah... llamado Ben Aknoun. (...) Cada uno de nosotros recibió, sabes, cama, cepillo de dientes, ah, sabes... nosotros bien... yo sin zapatos... en fin... no es solo sin papeles, sin nada... maltrecho, sucio, en fin. Nunca nadie se bañó allí ¿no?... algunos hacía meses, yo también, unos ensangrentados... esa es la cuestión (silencio)... quiero decir... nos sacaron de allí... o, entonces el shock de tú entrar a un lugar, sabes, limpio, dormir con sábanas, en fin, no tirado en el piso, esas cosas ¿no? Un shock muy, muy fuerte ¿no? Despertarse allí, árboles, pajaritos, había hasta unos conejitos que andaban por allí en aquel lugar" (Dowbor, 2017).

Aparece también, en los relatos y memorias, la mención al cariño de la población argelina con la cual los desterrados tuvieron contacto, pues habría una identificación con grupos que luchaban por la liberación en sus países de origen. No obstante, aún con la simpatía, 
debemos resaltar que la tentativa, por parte del gobierno argelino, de mantener al grupo reunido pudo estar relacionada con evitar que el conflicto escalara con el gobierno brasileño, ya que los dos países mantenían relaciones diplomáticas. Aun así, un mes después de la llegada del grupo, un telegrama de la Secretaría de Estado del Ministerio de Relaciones Exteriores brasileño a la embajada en Argel orientaba a que el embajador cuestionase a las autoridades del país magrebino acerca de la movilidad y las denuncias realizadas por el grupo, y solicitaba que ningún pedido de los desterrados debería ser atendido:

"Las circunstancias de su salida de Brasil y, especialmente, la condición de desterrados, les vedan cualquier derecho a contar con el amparo y la protección de las autoridades diplomáticas y consulares brasileñas. En esas condiciones, vuestra señoría no deberá atender ningún pedido que las referidas personas le realicen para la ejecución de los actos que usualmente pueden ser practicados en favor de los ciudadanos brasileños residentes en el exterior" ${ }^{25}$.

También se debe resaltar que la movilidad para otros países fue muy limitada, como demostró Martins Filho (2019) al analizar la documentación del servicio secreto británico, que orientaba a sus agentes a no permitir que brasileños desterrados entraran al país.

Al mismo tiempo, es importante destacar que en el grupo había militantes de varias organizaciones, de forma que algunos no se conocían. Así, al analizar fotografías del grupo ${ }^{26}$ percibimos que los que se conocían estaban siempre próximos a aquellos de su organización. También se debe remarcar que había mucha desconfianza, teniendo en cuenta que circulaba una idea de que los que supuestamente habían hablado bajo tortura no deberían estar en la lista. Es el síndrome de la traición, apuntado por Gasparotto (2008). Es importante que comprendamos que el grupo no era homogéneo y, aunque todos formaran parte de organizaciones de lucha armada, las estrategias adoptadas eran distintas y, por ello, no deberían ser compartidas abiertamente.

Los días siguientes a su llegada fueron numerosas las entrevistas concedidas por los desterrados a diferentes medios de comunicación,

25 Archivo Histórico del Itamaraty. Secretaría de Estado para Embajada en Argel. Telegrama. Presos políticos banidos para a Argélia. 17-VII-1970.

26 Disponibles en el acervo del Instituto Miguel Arraes, en Recife. 
sobre todo de Europa, como menciona Maria do Carmo: "Enseguida, el primer día, ya comenzó la rutina de dar entrevistas y hacer contactos. Aparecieron periodistas de las principales revistas y periódicos de Europa, que estaban ahí acampados." (Vianna, 2003: 104). A tales acciones, el gobierno dictatorial respondía que era "una campaña difamatoria" realizada por "malos brasileños".

En el segundo semestre de 1970, una acción organizada por Yara Gouvêa, en ese entonces exiliada en Suiza y cercana a la VPR, hizo que dos desterrados que todavía se encontraban en Argelia, Apolônio de Carvalho y Ladislau Dowbor, fueran hasta Suiza y participaran allí de innumerables acciones de denuncia contra la dictadura, inclusive en programas de televisión de alcance continental (Kreuz, 2020). El gobierno dictatorial actuó de manera sistemática para que esas acciones fuesen canceladas, lo que hizo que los dos desterrados retornaran para Argel e, inclusive, que la presencia de Yara se tornase inviable en el país europeo (Gouvêa y Birck, 2007). O sea, aun no estando en territorio nacional, el hecho de estar exiliados hizo que otras estrategias de acción fueran articuladas con la intención de denunciar la dictadura y debilitarla. Por eso, podemos comprender el exilio también como un espacio de resistencia, aunque pensado en moldes distintos de lo que ocurriría en Brasil.

Otro elemento que aparece en la memoria de los desterrados está relacionado con la presencia de Miguel Arraes, considerado el exiliado ilustre en el territorio argelino. A pesar de que no hubiera tanta sintonía, pues el líder pernambucano, de acuerdo con las evidencias, no apoyaba la lucha armada, hubo contactos entre los desterrados, además de que las relaciones con individuos de dichos grupos eran constantes. Una acción de gran destaque fue la tentativa de organizar una dirección colegiada para el Frente Brasileño de Informaciones (FBI), compuesta por militantes de diferentes grupos armados. El boletín, que contenía denuncias y análisis acerca de la dictadura brasileña, fue organizado a partir de Argel y se transformó en un importante espacio de acción transnacional. De a poco, su radio de acción se amplió, de manera que pasó a ser publicado en Chile, en Francia y en otros países. No obstante, con el pasar del tiempo, como Cruz (2011) demostró, la dirección colegiada se deshizo, de forma que en cada país los grupos se organizaron. 
Por último, es importante resaltar la memoria sobre la presencia de militantes de otros lugares del mundo, sobre todo de las colonias portuguesas. Ese contacto es recordado como un momento de intercambios y aprendizajes. Maria do Carmo, por ejemplo, afirma que todo lo que aprendió sobre falsificación de documentos fue a través de militantes mozambiqueños que se encontraban en Argelia (Vianna, 2003).

Así, luego del alivio inicial de haber salido de Brasil, individual o colectivamente, sobre todo con la articulación a partir de los grupos de lucha armada, se pasó a la fase de planificación de las siguientes acciones, teniendo en cuenta que ellos no se consideraban exiliados. $\mathrm{O}$ sea, para la mayoría, lo que se consideraba más factible era el retorno a Brasil.

Aproximadamente un mes después de la llegada al país, recibieron una invitación para que representantes de las organizaciones armadas fuesen a Cuba para participar de las conmemoraciones del aniversario de la Revolución, el día 26 de julio. A partir de entonces se inició otro proceso: el viaje a la isla caribeña sin dejar evidencias para las fuerzas represivas. Fayal (2017) afirmó que el viaje fue articulado entre el gobierno argelino y el cubano para que no fueran necesarios pasaportes. De esta forma, la mayor parte de los militantes viajó a ese país con el objetivo de realizar entrenamiento de guerrilla y retornar a Brasil. De acuerdo con lo que las evidencias señalan, permanecieron en Argel los militantes de la VPR, que necesitaban recuperar el dinero de la acción del cofre, Apolônio de Carvalho, que deseaba ir para el exilio en Francia, y Altair Campos, cuya familia fue a su encuentro y pasaron algunos años residiendo en Argelia $^{27}$.

Aún con la ida a Cuba, el retorno a Brasil, al menos en el corto plazo, no fue posible. La dictadura desmanteló las organizaciones de resistencia y aquellos que intentaron volver fueron asesinados ${ }^{28}$. Así, el proceso de retorno solo pudo ocurrir a partir de 1979, con la amnistía ${ }^{29}$.

27 En la obra Memórias de filhos de exilados políticos (2020) encontramos la mención de esa elección.

28 Ellos son: José Lavecchia, asesinado en 1970; Aderval Alves Coqueiro y Carlos Eduardo Pires Fleury asesinados en 1971; Jeová Assis Gomes, asesinado en 1972, y Eudaldo Gomes da Silva y Joaquim Pires Cerveira, asesinados en 1973.

29 Aún no existen muchos trabajos que analicen los procesos de retorno de los exiliados, sobre todo en Brasil. Para los casos argentino y uruguayo, consultar Lastra (2016). 
No es posible establecer una regla general para comprender la trayectoria de todos los desterrados, aunque podamos apuntar algunos elementos: cuando sucedió el destierro, los mismos no se consideraban exiliados y deseaban retornar a Brasil en un corto o mediano plazo. Esa perspectiva solo fue alterada cuando las organizaciones fueron desmanteladas y el exilio se tornó la nueva perspectiva. De a poco, la mayor parte de los desterrados adoptó prácticas políticas relacionadas con la defensa de los derechos humanos y, con la proximidad de la amnistía, sobre todo a partir de 1975 y en suelo europeo, esa fue la principal bandera de lucha.

\section{Conclusiones}

El presente artículo buscó presentar, de manera breve, el proceso de destierro de 40 militantes políticos hacia Argelia como consecuencia del secuestro del embajador alemán de esa época en Brasil, así como el corto proceso de permanencia, para la mayoría, en suelo argelino. Tal hecho sucedió en junio de 1970 y fue parte de un conjunto más amplio de acciones de resistencia.

Así, a partir de lo discutido, podemos presentar algunas conclusiones: la primera, sobre la utilización de los secuestros en tanto una estrategia de resistencia defensiva (Silva, 2020), teniendo en consideración que su repercusión hacía que las organizaciones supusieran tener una fuerza mayor de la que en realidad tenían. Asimismo, los secuestros fueron responsables por liberar de las cárceles dictatoriales a más de una centena de militantes, por lo tanto, fueron eficaces en su propósito, así como en el de, aunque momentáneamente, burlar la censura sobre las acciones políticas entonces desencadenadas. Para responder a estas acciones, la dictadura, por medio de un acto institucional, creó la pena de destierro del territorio nacional. A partir de entonces, los desterrados no poseían ningún tipo de documento y eran considerados sin nacionalidad. Como ha sido demostrado, sus fotografías pasaron a ilustrar los álbumes de las policías del mundo entero.

Argelia, por lo tanto, no fue un destino de exilio para los intercambiados. Es importante resaltar que ellos no se consideraban exiliados, pues pensaban que en breve pudiesen retornar a Brasil. El país magrebino representó, para la mayoría, apenas un periodo de recuperación de la tortura y de la prisión y la recomposición de sus contactos con 
sus organizaciones. Aquellos que permanecieron allí tenían objetivos distintos: Apolônio de Carvalho quería ir para Francia, Altair Lucchesi deseaba permanecer en el país y reencontrar a su familia, y los militantes de la VPR querían rearticularse. Al final de 1970 ellos viajaron a Chile. La proximidad con Miguel Arraes fue mayor entre aquellos que permanecieron en Argelia y también pasaron a componer la dirección del FBI.

Percibimos, a partir de lo expuesto, que la permanencia en Argelia se relacionaba, sobre todo, con la realización de diferentes formas de articulación. El monitoreo realizado por el aparato de vigilancia sobre las acciones de los militantes no era tan expresivo como el realizado en otros países, como en Chile. Podemos conjeturar que el gobierno argelino, por su posición ante los diferentes grupos revolucionarios que poseían representación en el país, no permitía tales acciones, aunque la embajada brasileña constantemente informara sobre las acciones realizadas por los exiliados.

Finalmente, es importante remarcar que la dictadura de seguridad nacional cercenó, de diferentes formas, el ejercicio de los derechos de nacionales en el exterior, sobre todo negando documentos. Solo recientemente este elemento ha sido problematizado por la historiografía, así como también las acciones realizadas por los militantes fuera del territorio brasileño y los diferentes tránsitos revolucionarios realizados. Esa tarea todavía está en desarrollo y debe ser objeto de nuevas reflexiones para que comprendamos la complejidad de la represión y también la resistencia a la dictadura.

\section{Referencias bibliográficas}

\section{Fuentes primarias}

\section{a) Entrevistas}

Aarão Reis Filho, D. Rio de Janeiro, RJ: 22-III-17. Entrevistadora: Débora Strieder Kreuz. Archivo de audio: 1 hora y 3 minutos.

Dowbor, L. Porto Alegre, RS: 19-X-17. Entrevistadora: Débora Strieder Kreuz. Archivo de audio: 1 hora y 27 minutos.

Lyra, C. E. F. Rio de Janeiro, RJ: 21-III-17. Entrevistadora: Débora Strieder Kreuz. Archivo de audio: 1 hora y 19 minutos. 
Vieira, L. B. Rio de Janeiro, RJ: 22-III-17. Entrevistadora: Débora Strieder Kreuz. Archivo de audio: 47 minutos.

b) Memorias

Benjamin, C. (2013). Gracias a la vida: memórias de um militante. Rio de Janeiro: José Olympio.

Carvalho, A. (1997). Vale a pena sonhar. Rio de Janeiro: Rocco.

Dowbor, L. (2000) O mosaico partido: a economia além das equações. Petrópolis (RJ): Vozes.

Gouvêa, Y. y D. Birck (2007). Duas Vozes. São Paulo: Editora de Cultura.

Paiva, M. (2004). O sonho exilado. Rio de Janeiro: Mauad.

Vianna, M. (2003). Uma tempestade como a sua memória: a história de Lia, Maria do Carmo Brito. Rio de Janeiro: Record.

Vieira, L. (2008). A busca: memórias da resistência. São Paulo: Editora Hucitec.

c) Archivos

Arquivo Histórico do Itamaraty. Secretaria de Estado para Embaixada em Argel. Telegrama. Presos políticos banidos para a Argélia. 17-VII-1970.

Arquivo Nacional. Centro de Informações da Aeronáutica. Elementos banidos do território nacional. 24-VI-1970. Identificación: BR_DFANBSB_Z4_SNA_TRR_0018_p161-162

Arquivo Histórico do Itamaraty. Secretaria de Estado para Embaixada em Argel. Telegrama. Presos políticos banidos para a Argélia. 17-VII-1970.

Fuentes secundarias

a) Artículos y capítulos de libros

Aquino, M. A. (2002). "Mortos sem sepultura”, en Carneiro, M. L. T. (org). Minorias Silenciadas: História da Censura no Brasil. São Paulo: Editora da Universidade de São Paulo, pp. 513532.

Camargo, A. M. A. (2002). “Os arquivos da polícia política como fonte”, en Registro, Indaiatuba, $\mathrm{N}^{\circ} 1$, pp. 5-11.

Gasparotto, A. (2008). "A síndrome da traição: Apontamentos sobre a figura do "traidor" nas organizações de combate à ditadura brasileira”, en Silva, C. L., G. Calil y P. J. Koling, Estado e 
poder: abordagens e perspectivas. Cascavel: Edunioeste, pp. 167-190.

Jensen, S. I. (2011). "Exilio e Historia Reciente. Avances y perspectivas de un campo en construcción", en Aletheia, Vol. 1, № 2.

Rollemberg, D. (1999) Exílio: entre raizes e radares. Rio de Janeiro: Record.

Sales, J. R. (2015). Guerrilha e Revolução: a luta armada contra a ditadura militar no Brasil. Rio de Janeiro: Lamparina.

Silva, C. L. (2020) "Sequestros e terrorismo de Estado no Brasil: casos de resistência revolucionária”, en Izquierdas, Vol. 49, pp. 1646-1669.

b) Libros

Alves, M. H. M. (1985). Estado e oposição no Brasil (1964-1984). Petró-

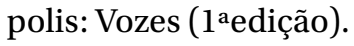

Assembleia Legislativa do Estado de São Paulo; Comissão da Verdade Rubens Paiva (2014). Infância Roubada: crianças atingidas pela ditadura militar no Brasil. São Paulo: ALESP.

Boiteux, B. C. y V. M. C. Postigo (2020). Memórias de filhos de exilados políticos. Rio de Janeiro: Mourthé.

Comissão Nacional da Verdade (2014). Relatório final. Brasília: CNV.

Da-Rin, S. (2007). Hércules 56: o sequestro do embaixador americano em 1969. Rio de Janeiro: Jorge Zahar.

Gorender, J. (2014). Combate nas Trevas. São Paulo: Expressão Popular.

Ishaq, V., P. E. Franco y Tereza E. Souza (2012). A escrita da repressão e da subversão (1964-1985). Rio de Janeiro: Arquivo Nacional.

Jensen, S. I. (2007). La provincia flotante: el exilio argentino en Cataluña (1976-2006). Barcelona: Fundación Casa América Catalunya.

Lastra, M. S. (2016). Volver del exilio: Historia comparada de las políticas de recepción en las posdictaduras de la Argentina y Uruguay (1983-1989). La Plata: Universidad Nacional de la Plata.

Lemos, R. L. C. (2018). Ditadura, anistia e transição política no Brasil (1964-1979). Rio de Janeiro: Consequência.

Martins Filho, J. R. (2019). Segredos de Estado: o governo britânico e a tortura no Brasil (1969-1976). Salvador: Saga Editora.

Sznajder, M. y L. Roniger (2013). La política del destierro y el exilio en América Latina. México: Fondo de Cultura Económica. 
Yazbek, M. (2010). A revolução argelina. São Paulo: Ed. UNESP.

Yankelevich, P. y S. Jensen (2007). Exilios: destinos y experiencias bajo la dictadura militar. Buenos Aires: Zorzal.

c) Otros

Cruz, F. L. (2011). Frente Brasileño de Informaciones e Campanha: os jornais de brasileiros exilados no Chile e na França (19681979). Dissertação para obter o grau de mestre em História. Universidade de São Paulo: São Paulo.

Dias, C. M. A. (2019). Minha terra tem horrores: o exílio dos brasileiros no Chile (1970-1973). Tese para obtenção do grau de doutora em História. Porto Alegre: Universidade Federal do Rio Grande do Sul, Brasil.

Kreuz, D. S. (2020). Da "Meca da Revolução" a "um país vazio": o exílio brasileiro na Argélia (1965-1979). Tese para obtenção do grau de doutora em História. Porto Alegre: Universidade Federal do Rio Grande do Sul, Brasil.

Resende, P. A. (2019). Ser um embaixador não é um mar de rosas: o sequestro de Charles Burke Elbrick no Brasil em 1969. Tese para obtenção do grau de doutora em História. São Paulo: Universidade de São Paulo, Brasil. 